\title{
A non-stochastic portfolio model for optimizing the transformation of an even-aged forest stand to continuous cover forestry when information about return fluctuation is incomplete
}

\author{
Katharina Messerer $^{1}$ - Hans Pretzsch ${ }^{2}$ - Thomas Knoke ${ }^{1}$
}

Received: 12 October 2016 / Accepted: 3 May 2017 / Published online: 24 May 2017

(C) The Author(s) 2017. This article is an open access publication

\begin{abstract}
- Key message Non-stochastic portfolio optimization of forest stands provides a good alternative to stochastic meanvariance optimization when available statistical data is incomplete. The suggested approach has a theoretical background in the areas of robust optimization, continuous multicriteria decision-making, and fuzzy theory. Resulting robust portfolios only show slight economic losses compared to the efficient frontier of a stochastic optimization.

- Context Economic optimization addressing diversification in mixed uneven-aged forest stands is a useful tool for forest planners.

- Aims The study aims to compare two approaches for optimizing rotation age cohort portfolios under risk. Rotation age
\end{abstract}

\section{Handling Editor: Rasoul Yousefpour}

Contribution of the co-authors K. Messerer had the main responsibility for writing the paper and analyzing the data. H. Pretzsch provided and processed input data. T. Knoke was involved in project planning and supported data analysis.

Katharina Messerer

katharina.messerer@tum.de

Hans Pretzsch

Hans.Pretzsch@1rz.tu-muenchen.de

Thomas Knoke

knoke@forst.wzw.tum.de

1 Institute of Forest Management, TUM School of Life Science Weihenstephan, Technische Universität München, Hans-Carl-von-Carlowitz-Platz 2, Freising, Germany

2 Chair of Forest Growth and Yield Science, TUM School of Life Science Weihenstephan, Technische Universität München, Hans-Carl-von-Carlowitz-Platz 2, Freising, Germany cohorts emerge from age-based regeneration-harvesting operations simulated for two tree species: Picea abies and Fagus sylvatica.

- Methods The first optimization approach is a stochastic mean-variance approach. The second is a non-stochastic optimization approach, which has rarely been applied to optimize tree species composition and the distribution of harvested timber over many periods. It aims at relatively good solutions, even if the deviation from the initially assumed return is very high. The objective function for both approaches is sensitive to the selection of various harvesting periods for different parts of the stand. For the stochastic approach, the objective function maximizes the annuitized net present value (economic return) for specific levels of risk by allocating area proportions to harvesting periods and tree species. In the non-stochastic approach, the allocation of area proportions instead minimizes the maximum deviation from the greatest possible economic return among many uncertainty scenarios (non-stochastic approach).

- Results Portfolios from both approaches were diverse in rotation age cohorts. The non-stochastic portfolios were more diverse when compared with portfolios from the efficient frontier, which showed the same standard deviation. However, P. abies clearly dominated the non-stochastic portfolios, while stochastic portfolios also integrated beech to a greater extent, but only in very low risk portfolios. The economic losses of the non-stochastic portfolios compared to the efficient frontier of the mean-variance approach lay between 1 and 3\% only for different levels of accepted risk.

- Conclusion The non-stochastic portfolio optimization over a large uncertainty space is so far uncommon in forest science, yet provides a viable alternative to stochastic optimization, particularly when available data is scarce. However, further research should consider ecological effects, such as increased resistance against hazards of conifers in mixed stands. 
Keywords Risk $\cdot$ Portfolio theory $\cdot$ Linear programming . Uncertainty $\cdot$ Robust optimization $\cdot$ Fuzzy theory $\cdot$ Forest economics $\cdot$ Forest management $\cdot$ Continuous cover forestry

\section{Introduction}

Forest managers are confronted with many risks and uncertainties. The frequency of natural disturbances like storms, fire, and landslides, damage from insects such as bark beetles, and stand failures could even increase in the context of climate change (Coumou and Rahmstorf 2012; Intergovernmental Panel on Climate Change 2014; Petoukhov et al. 2016; Rahmstorf and Coumou 2011). The impacts of disturbances represent an enormous economic loss for European forests (Hanewinkel et al. 2012). Consequently, forest decision makers will face great challenges. Many forest science studies conclude that continuous cover forestry may be the best way to compensate for natural disturbances and uncertainties (Ciancio et al. 2006; Huth and Wagner 2013; Knoke 2009; Pukkala 2016; Schütz 2001). There is a wide range of continuous cover forestry models, and these management systems are spread, albeit sparsely, all over the world (Pommerening 2004; Pretzsch et al. 2015). The three key aspects of continuous cover forestry are as follows: the avoidance of clear cutting, highly structured stands and site-adapted or native tree species (Davies et al. 2008). These characteristics all lead to more resistant forest stands and consequently the stands are better able to withstand disturbance. There are also many other benefits of continuous cover forestry, such as maintaining high biodiversity, providing continuous economic revenues, and providing ecosystem services, such as erosion control (Pommerening 2004; Schütz 2001). However, it is still unclear if the consideration of uncertainty would actually support uneven-aged silviculture.

Several approaches exist to consider uncertainty in forest science studies. Yousefpour et al. (2012) reviewed the decision-support tools available to help foresters handle the upcoming challenges. Thus, in the past, several financial techniques to quantify and consider these risks and uncertainties have been developed to integrate them into management decision-making. In forestry, most economic approaches to consider risks and uncertainties have drawn on the stochastic expected utility framework or option pricing theory. Referring to this framework, three stochastic approaches that draw on the expected utility framework are stochastic dominance, downside risk, and mean-variance models. Stochastic dominance differentiates between efficient and inefficient outcomes. However, it cannot rank two efficient options, like two profitable management systems. Downside risk and meanvariance models use the standard deviation of economic return to quantify risk. The two approaches differ in that a downside risk model considers risk as a possible result that is worse than a pre-defined threshold, whereas a mean-variance approach maximizes return for pre-defined levels of risk (Hildebrandt and Knoke 2011).

Option pricing models focus on the desirable part of uncertainty (i.e., positive deviations from the expected value). They assume that decisions may be adjusted during the considered time horizon and hence quantify the "value" of flexibility (Wilson and Baker 2001; Yemshanov et al. 2015). For instance, Yemshanov et al. (2015) demonstrated the differences in opportunity costs of land-use change when calculated conventionally and when calculated by an option pricing model. They found that afforestation as a land-use change reduces management flexibility, which may well explain the reluctance of landowners to convert agricultural land use to forest plantations. However, we shall keep in mind that the reluctance of landowners to convert agriculture towards forestry is also a matter of psychological and social factors, such as general attitude to property and ancestors.

Robust optimization is another important approach for including uncertainties in management decisions (Gabrel et al. 2014). Knoke et al. (2015) have shown the relation between robust optimization, when adopted as a constraint-based version (Ben-Tal et al. 2009), and the MINMAX formulation of a Goal Programming problem (Tamiz et al. 1998). This robust MINMAX approach, however, does not belong to the before mentioned framework of expected economic utility, because it is non-stochastic. Still, this approach uses a specific utility function, where a high maximum difference between the ideal achievement level and the level actually achieved contributes to the decision makers' disutility. The optimization of such MINMAX utility functions implicitly means minimizing non-achievement (Romero 2001). Following this approach, our non-stochastic programming procedure will implicitly minimize the difference between maximum achievement levels for economic return and actually achieved levels among all considered combinations of the uncertain input parameters (uncertainty scenarios). In this study, the economic return is expressed as the annualized net present value (NPV) of different rotation age cohorts (annuities). Furthermore, we will show that this approach can also be regarded as a MAXMIN problem in a fuzzy theory framework, and we will point out its differences from information-gap decision theory. Consequently, the introduced portfolio approach has strong theoretical support from various research areas.

To the best of the authors' knowledge, there are hardly any similar portfolio based studies of non-stochastic optimization in forest management decision-making. One of the rare examples for robust optimization (however, not based on portfolio theory) is Palma and Nelson (2009), who optimized harvest scheduling with 15 different management options (all of which involved clear-cutting), and included volume and demand as the uncertain variables. The objective function was to maximize the revenues from harvesting and at the same time maximize the value of the remaining stand. They compared 
the "difference in the decisions' stability" (Palma and Nelson 2009) of the robust optimization and a deterministic model, and concluded that the costs of increasing robustness were acceptable. In the present study, we apply non-stochastic, robust portfolio optimization as a tool to analyze a possible transformation of an even-aged forest stand to continuous cover forestry to improve and facilitate optimization-supported decisions. We compare this new, robust approach to optimize the composition and management of a forest stand with the classical mean-variance optimization, as introduced by Roessiger et al. $(2011,2013)$ for a similar analysis. The starting point in our study and in the Roessiger et al. (2011) study is an even-aged forest, for which the management is not pre-defined. The applied optimization approach will suggest whether or not a clear cutting of a pure stand is a preferable management strategy, or if the distribution of regeneration harvests over many periods in a mixed forest is the better option, if uncertainties have to be addressed.

\subsection{Short overview about existing literature}

The starting point for testing our non-stochastic optimization approach for its appropriateness to optimize forest management was Markowitz' $(1952,2010)$ modern portfolio theory (MPT). This stochastic method considers the portfolio return as a random variable and integrates risk as the standard deviation of the expected portfolio return. The portfolio's standard deviation is derived from the sum of all return covariances, which implicitly assumes normally distributed economic returns of the individual portfolio options. In the literature, many applications of classical portfolio theory to support decision-making around environmental questions can be found. The frequent use underlines the importance of optimization tools for analyzing benefits and trade-offs of diversification. Production fields such as agriculture (Abson et al. 2013) and fisheries (Edwards et al. 2004), as well as landuse management (Knoke et al. 2013), economic analyses under uncertainty, risk diversification effects, and the valuing of biodiversity (Figge 2004; Raes et al. 2016) have all been supported, among other methods, by a mean-variance approach. Many applications can also be found in forest science (Hildebrandt and Knoke 2011). Neuner et al. (2013), for example, tested the applicability of portfolio theory to support the choice of tree species in private forest estates. Hahn et al. (2014) used data from a Bavarian municipal forest to demonstrate how uncertainties, and risks could be integrated into management plans through mean-variance portfolio optimization. This optimization model also leads to an optimal treatment of the forest stands for small-scale, private forest owners who are strongly risk-averse (Roessiger et al. 2011). The model presented by Roessiger et al. (2011) will be used as a reference for the results of our suggested non-stochastic portfolio approach.
The portfolio optimization method is also used to demonstrate how carbon sequestration of forests could be optimized and how future resilient forest stands, in the context of climate change, should be established and managed. Dragicevic et al. (2016) optimized wood production, which also leads to a higher carbon sequestration and results in portfolios similar to those that are directly optimized for carbon sequestration. Weng et al. (2013) calculated the future composition of black spruce (Picea mariana) reforestations that were optimized to maximize yield and minimize risk, with models based on the portfolio theory. The authors balanced growth and stability and compared them to common truncation-deployment approaches. While both approaches produced similar results, the portfolio theory approach was recommended for optimization if yield stability is important.

The studies mentioned above have optimized, for example, portfolios for fish populations, biodiversity, genes, land use, different tree species, and forest stand types. They quantify the advantages of management decisions under uncertainty using mathematical programming approaches, such as non-linear programming, and can integrate further management aspects like carbon sequestration. However, many studies have identified limitations of classical mean-variance portfolio optimization approaches.

Classical portfolio optimization requires information on all return covariances among the considered assets (Knoke et al. 2015). In contrast to decisions about investments in financial stocks, where data is delivered from stock markets, financial data is scarce when considering natural ecosystems and their management. If insufficient data is available, data must be generated through simulation techniques, such as Monte Carlo Simulation (MCS) (to start), to integrate uncertainties like timber price fluctuations, disturbance events, changing management, or afforestation costs (e.g., Roessiger et al. 2011). To generate the necessary economic data, information on past costs and prices must be used, with the assumption that the future will mimic the past. The standard deviation of each portfolio asset, the correlations between all assets, and the resulting standard deviation of the whole portfolio are all needed for the optimization (Markowitz 1952). In contrast, the non-stochastic optimization can be performed based on very limited data (Knoke et al. 2015).

In addition to their high data demand, stochastic optimization approaches may be limited by the fact that the composition of the resulting portfolios is highly sensitive to changes in the initial parameters (see Beinhofer 2009 for forestry examples and Goldfarb and Iyengar 2003 for selection of financial portfolios). Such changes may be necessary, for example, because of (systematic) estimation errors in means, variances, and covariances (Ziemba and Mulvey 1998). For example, climate change can alter growth conditions, which can in turn change the optimal composition of the portfolio (Härtl et al. 2016). 
To circumvent these disadvantages, Knoke et al. (2015) applied a non-stochastic optimization model to agricultural land-use portfolios. This new approach could be advantageous for forest management because it requires less data and no information about correlations between the single assets. Additionally, the resulting portfolio weights (in our study, the allocated area to each rotation age cohort) may be less variable when risk aversion changes. The reduced information requirement of the non-stochastic optimization approach is a particular advantage in a forestry environment, where data is often scarce or incomplete.

It is important to note that the mentioned robust optimization differs from sensitivity studies, which are "post mortem tool(s)" (Ben-Tal and Nemirovski 2000, p. 413): robust optimization incorporates uncertainties already into the optimization procedure and results in an optimal solution that only changes slightly across varying initial coefficients (Lin et al. 2004). Uncertainty scenarios cover the variation in the coefficients a priori and constraints guarantee acceptability of the achieved solution over a wide range of input coefficients. Thus, over the wide range of considered parameter perturbations, results stay acceptable (Kangas et al. 2008; Knoke et al. 2015). In contrast, sensitivity analyses evaluate the possible range of results by a variation of the input parameters only ex post, after having obtained the optimal solution (Albadvi and Koosha 2011; Ben-Tal and Nemirovski 2000).

\subsection{Structure of the paper}

Our study therefore aims to test the applicability of the outlined novel approach in forest management planning and decision-making in the context of a possible transition from even-aged forestry to continuous cover forestry. The study uses data sets representing up-to-date growth data to identify advantages and shortcomings of the non-stochastic optimization. By comparing the results of the non-stochastic model to a traditional portfolio based efficient frontier, we investigate possible losses through non-stochastic optimization and the differences in the derived portfolio composition. Finally, we identify promising fields for future research.

The main research question asked in the present study is as follows: How do stand composition and management differ when comparing a classical portfolio optimization with a nonstochastic, robust portfolio optimization? The paper is divided into five sections. The first (current) section gives a brief overview of forest optimization modeling and the integration of risks and uncertainties. The next section presents the classical portfolio approach to forestry. The new forest optimization methodology is then described in Sect. 3. In Sect. 4, both methods are applied to a specific case study. Results are compared in the fifth section. In the final section, we discuss our results and draw conclusions.

\section{Material and methods}

\subsection{Classical portfolio approaches in forestry}

Previous studies applying the mean-variance approach have used the economic return of each portfolio asset and correlations between them, using the standard deviation of the economic return of the portfolio as the uncertainty measure. To start our study, we formulate a particular problem for optimizing the composition of a forest stand regarding different rotation age cohorts and tree species as follows

$\max E\left(Y_{L}\right)=\sum_{i \in L} E\left(y_{i}\right) a_{i}$

subject to

$$
\begin{aligned}
& S_{L} \leq S_{A} \\
& S_{L}=\sqrt{\sum_{i \in L} \sum_{j \in L} a_{i} a_{j} \operatorname{cov}_{i, j}} \\
& \sum_{i \in L} a_{i}=1 \\
& \operatorname{cov}_{i, j}=k_{i, j} s_{i} S_{j} \\
& a_{i} \geq 0
\end{aligned}
$$

Rotation age cohorts refer to the planned felling age for a specific part of the forest stand expressed as a percentage fraction of the stand area. The maximization of the economic return $\left(€ \mathrm{ha}^{-1}\right.$ year $\left.^{-1}\right)$ of the portfolio $\left(Y_{L}\right)$ is reached by an optimal composition of the allocated land areas $\left(a_{i}\right)$ to single rotation age cohorts $(i)$, created at only one or at various periods, for different tree species. We considered the harvesting and thus the regeneration timings as rotation age cohorts and assume that regeneration harvests will stimulate natural regeneration (adapted game populations provided). For example, allocating a percentage fraction of $10 \%$ to the rotation age cohort Norway spruce (Picea abies) with age 80 years ( $\mathrm{Sp}$ 80 ) means that $10 \%$ of the forest area will be harvested consisting of spruce at age 80 years. This area will be regenerated at this age (see Table 1). The set of all considered rotation age cohorts, which in this study is composed of eight for Norway spruce and nine for European beech, is denoted by $L$. All rotation age cohorts provide a specific economic return, in this study an average annual payment (annuity), depending on harvesting timing and tree species $\left(y_{i}\right)$. The expected return $E\left(y_{i}\right)$ is calculated through averaging 10,000 MCS. MCS include uncertainties such as wood price fluctuations, disturbance events, and changing management costs (see Roessiger et al. 2011 and Sect. 2.3.1 for details on the simulation approach). The standard deviation $\left(s_{i}\right)$ of the returns of the rotation age cohorts and correlations $k_{i, j}$ between the different rotation age cohorts $i$ and $j$ were used to calculate covariances $\left(\operatorname{cov}_{i}\right)$ and the standard deviation of the whole portfolio $\left(S_{L}\right) . S_{A}$ is a pre-defined standard deviation and hence the accepted maximum risk level, which is used to calculate the efficient frontier. The efficient frontier consists of portfolios with maximal economic return for a certain level of risk, 
Table 1 Annuities in $€$ ha $^{-1}$ year $^{-1}$ and standard deviations of all rotation age cohorts

\begin{tabular}{lcc}
\hline $\begin{array}{l}\text { Rotation age } \\
\text { cohort }(i)\end{array}$ & $\begin{array}{l}\text { Average annual } \\
\text { payment (annuity) }\end{array}$ & $\begin{array}{l}\text { Standard } \\
\text { deviation }\end{array}$ \\
\hline Norway spruce $30(\mathrm{Sp} 30)$ & 150 & 100 \\
Norway spruce $40(\mathrm{Sp} 40)$ & 313 & 138 \\
Norway spruce $50(\mathrm{Sp} 50)$ & 390 & 161 \\
Norway spruce $60(\mathrm{Sp} 60)$ & 397 & 168 \\
Norway spruce $70(\mathrm{Sp} 70)$ & 380 & 167 \\
Norway spruce $80(\mathrm{Sp} 80)$ & 351 & 160 \\
Norway spruce $90(\mathrm{Sp} 90)$ & 312 & 147 \\
Norway spruce $100(\mathrm{Sp} 100)$ & 281 & 137 \\
European beech $40(\mathrm{Be} 40)$ & -145 & 7 \\
European beech $50(\mathrm{Be} 50)$ & -62 & 18 \\
European beech $60(\mathrm{Be} 60)$ & -11 & 25 \\
European beech $70(\mathrm{Be} 70)$ & 21 & 30 \\
European beech $80(\mathrm{Be} 80)$ & 36 & 32 \\
European beech $90(\mathrm{Be} 90)$ & 47 & 34 \\
European beech $100(\mathrm{Be} 100)$ & 49 & 34 \\
European beech $110(\mathrm{Be} 110)$ & 46 & 33 \\
European beech $120(\mathrm{Be} 120)$ & 45 & 33 \\
\hline
\end{tabular}

expressed by a specific standard deviation. The allocated relative percentage fractions must sum to 1 and cannot be negative values.

\subsection{Non-stochastic portfolio approach}

The non-stochastic optimization model applied in this paper follows a suggestion by Knoke et al. (2015), who referred to an example of robust optimization introduced by Ben-Tal et al. (2009) and used the approach for optimizing agricultural land-use portfolios. This non-stochastic approach allows for linear programming, which makes sure that the global optimum will be found. The approach is adapted for the purpose of the present study as follows

$\max Y_{L}=\sum_{i \in L} y_{i} a_{i}$

subject to

$\sum_{i \in L} y_{s i}{ }^{*} a_{i} \geq \max \left(y_{s i}\right)-\beta_{U}{ }^{*} \delta_{\max , \min } \forall s \in S$

$y_{s i}=y_{i} \pm u_{s i}$

$0 \leq \beta_{U} \leq 1$

$\sum_{i \in L} a_{i}=1$

$a_{i} \geq 0$

$Y_{L}$ is the annuity of the entire forest stand portfolio $\left(€\right.$ ha $^{-1}$ year $\left.^{-1}\right)$ when applying the nominal return coefficients. Each of the single rotation age cohorts $i$ has a nominal annuity, $y_{i}$, $\left(€\right.$ ha $^{-1}$ year $\left.^{-1}\right)$. This nominal annuity used for the present study is represented by the mean of the results from a MCS with 10,000 repetitions. For the following optimization process, a possible minimum or maximum annuity, $y_{s i}$, was created for each rotation age cohort $i$ through subtracting or adding a possible deviation, $u_{s i}\left(€ \mathrm{ha}^{-1} \mathrm{year}^{-1}\right)$, from or to $y_{i}$. This deviation can be viewed as an uncertainty factor and is expressed in this study as

$u_{s i}= \pm m^{*} s_{i}(m=1.0,1.1,1.2, \ldots, 2.8,2.9,3.0)$

where $m$ is a multiplication factor which defines the size of the uncertainty space, and thus, $u_{s i}$ is the maximal possible deviation from the initial annuity coefficient, $y_{i}$. The range of 1.0 to 3.0 for this factor $\mathrm{m}$ was chosen to investigate the impact of the size of the uncertainty spaces on the portfolio composition. A manager with a lower degree of risk aversion could choose a smaller multiplication factor $m$ than a more risk averse one. The upper limit was taken from Knoke et al. (2015) who considered three times the standard deviation as adequate for simulating a very large uncertainty space. The multiples 1.0 up to 3.0 in 0.1 steps were used to create the deviations $\left(u_{s i}\right)$ (the higher the uncertainty factor $u_{s i}$, the greater the level of risk aversion and the more uncertainties like price fluctuations, stand failure, or silvicultural treatment are included). By creating all possible combinations of the 17 possible positive or negative deviating annual payments, $y_{s i}$, of the given rotation age cohorts (eight spruce and nine beech rotation age cohorts), $i$, a great number of uncertainty scenarios, $s\left(2^{17}=131,072\right)$, were generated. Within each uncertainty scenario, there exists a maximum annuity $\left(€\right.$ ha $^{-1}$ year $\left.^{-1}\right)$, $\max \left(y_{s i}\right)$, a minimum annuity, $\min \left(y_{s i}\right)$, and consequently a maximum range, $\delta_{\max , \min }$, between both. $S$ is the set of all 131,072 uncertainty scenarios generated for this study. Each uncertainty scenario is represented by an appropriate constraint in Eq. 2. Optimization was also carried out with only negative deviations from the nominal values, which were considered as the upper limits, to investigate the effect of only allowing for downside deviations.

The variables $a_{i}$ are percentage fraction (i.e., area proportions) allocated to the considered rotation age cohorts (decision variables), similar as in Eq. 1. The maximum annuity and the maximum range, $\delta_{\max }$, min , of each uncertainty set define ultimately the exact constraints for the optimization process. A control factor, $\beta_{U}$, to scale "the degree to which the constraint has to be relaxed" (Knoke et al. 2015) to achieve the optimal portfolio is integrated in the formula (see below for a more detailed look at this control factor).

The uncertainty spaces are multidimensional boxes considered to model the possible return variability and return combinations for all rotation age cohorts. The extreme combinations of the deviated expected annuities (maximum-maximum, maximumminimum, minimum-maximum and minimum-minimum) form the corners of the boxes, when only two options are considered. All possible combinations of the parameters and consequently all 
possible outcomes in the form of annuities are implicitly included in these square uncertainty scenarios. The obtained solutions have to be feasible for the border of the uncertainty set in order to be feasible for all possible combinations. For this reason, no exact distribution of the possible values is needed to support the robust optimization approach and thus the method may be applied for all distribution types.

\subsubsection{Control factor $\beta_{U}$}

The control factor, $\beta_{U}$, is a measure of the greatest distance from the best possible result which we have to tolerate to obtain acceptable results for all uncertainty scenarios. This distance depends, inter alia, on the size of the considered uncertainty set, $U$, and thus on the multiplication factor for the standard deviation. This control factor is minimized iteratively to the lowest possible value for a given size of the uncertainty space. For all $\beta_{U}$ smaller than a specific threshold value, the problem will become infeasible. The control factor $\beta_{U}$ can range between 0 and 1 . If it is close to 0 , only annuities close to the maximum annuity possible for each uncertainty scenario will be accepted; the imposed constraint on the acceptable annuity does not allow lower annuities. In contrast, if the control factor tends to 1 , only close to minimum annuities are required by the forest manager for the optimization process.

According to Knoke et al. (2015), re-arranging the constraint in Eq. (2) leads to the following consideration (Eq. 4)

$D_{i}=\frac{\max \left(y_{s i}\right)-\sum_{i \in L} y_{s i}{ }^{*} a_{i}}{\delta_{\max , \min }}$

$D_{i}$ quantifies each deviation of actually achieved return from the highest possible return, standardized by means of the distance between maximum and minimum return. It would now be possible for the optimization to directly minimize the variable $D_{i}$ to get the smallest control factor (Knoke et al. 2015), following the below mathematical formulation.

$$
\begin{aligned}
& \min [\max (D)] \\
& \frac{\max \left(y_{s i}\right)-\sum_{i \in L} y_{s i}{ }^{*} a_{i}}{\delta_{\text {max }, \text { min }}} \leq D \quad \forall s \in S
\end{aligned}
$$

This formulation is equivalent to a MINMAX problem of a Goal Programming approach (Romero 2001; Tamiz et al. 1998). The constraint in Eq. 5 is helpful to control the achievement of a global minimum, because the objective function (Eq. 4) is no longer smooth. Actually, our optimization followed Eq. 5; however, it was tested manually if a proposed minimum D could still be reduced, without violation of any constraint. By checking this, we made sure that local minima have been avoided.

\subsubsection{Fuzzy theoretic interpretation}

Replacing "crisp" objective functions and constraints by "fuzzy" versions is an opportunity to introduce fuzzy theory into programming methods. Fuzzy theory is an approach to consider uncertainty or ambiguity in general. It may also inform forest management decisions (Kangas and Kangas 2004; Pasalodos-Tato et al. 2013). A fuzzy formulation of Eq. 2 can be achieved as follows (Eq. 6) (see, for example, Mendoza and Sprouse 1989)

$$
\begin{aligned}
& \sum_{i \in L} y_{i}^{*}{ }^{*} a_{i} \gtrsim Y_{o} \\
& \sum_{i \in L} y_{s i}{ }^{*} a_{i} \gtrsim \max \left(y_{s i}\right) \quad \forall s \in S \\
& \sum_{i \in L} a_{i}=1 \\
& a_{i} \geq 0
\end{aligned}
$$

Here, approximate formulations $(\gtrsim)$ replace the precise "greater than or equal to" and "less than or equal to" signs. In Eq. 2, $Y_{o}$ would represent the maximum nominal economic return of the portfolio, which needs to be achieved only approximately. Fuzzy problems, therefore, do not look for precise best solutions, but rather for "good enough" solutions. To solve Eq. 6, it is essential to form membership functions, in our case, one for each of the uncertainty scenarios, $s$. These would impose admissible deviations from the desired target levels (aspiration levels) and allocate either 0 (constraint not met) or 1 (constraint met) or achievement level values between 0 and 1 (constraint partly met) to the economic returns achieved under a specific uncertainty scenario. Equation 7 shows a possible formulation for a membership $\left(m_{s}\right)$ function in our case. Using $Y_{L s}=\sum_{i \in L} y_{s i}{ }^{*} a_{i}$ for the return of the forest portfolio under various uncertainty scenarios, $s$, we can write for a specific uncertainty scenario

$m_{s}\left(Y_{L s}\right)=\left[\begin{array}{ccc}1 & \text { for } & Y_{L s}=\max \left(y_{s i}\right) \\ 1-\frac{\left[\max \left(y_{s i}\right)-Y_{L s}\right]}{\delta_{\max , \min }} & \text { for } & \max \left(y_{s i}\right)>Y_{L s}>\min \left(y_{s i}\right) \\ 0 & \text { for } & Y_{L s}=\min \left(y_{s i}\right)\end{array}\right]$

In Eq. 7, the maximum possible deviation from the required target level is $\delta_{\max }$, min. An appropriate objective function to solve this fuzzy problem is then a MAXMIN function (Eq. 8).

$M=\max \left\{\min \left[m_{s}\left(Y_{L s}\right)\right]\right\}$
$\frac{Y_{L s}-\min \left(y_{s i}\right)}{\delta_{\text {max }, \text { min }}} \geq M \quad \forall s \in S$

This means that we look for the minimum membership level among all membership functions, with one function for each uncertainty scenario, $s$. Then, we maximize this minimum membership level, with $M$ being the final maximum worst-case membership level. This is equivalent to minimizing the maximum deviation from the desired target levels 
(MINMAX problem), as described under Sect. 2.2.1. Thus, we may also consider our non-stochastic optimization problem as a fuzzy formulation of the constraint-based portfolio approach.

Both interpretations as a Goal Programming problem and as a fuzzy theoretic problem underline the theoretical appropriateness of the robust, non-stochastic optimization approach.

\subsubsection{Comparison with info-gap decision theory}

Information-gap decision theory (info-gap from here onwards) is another non-stochastic alternative to address uncertainty. This theory considers the result of a decision in form of a reward function, $R(q, u)$ (Ben-Haim 2006). This reward depends on the decision, $q$, which may be the allocation of area fractions to forestry options, and on the uncertainty, $u$. The uncertainty may be described by various so-called information-gap uncertainty models. To improve the immunity of a decision against adverse uncertainty, an immunity function is maximized with the aim to always satisfy the minimal requirements for all $u$.

$\alpha\left(q, r_{c}\right)=\max \left\{\alpha:\left(\min _{u \in U(\alpha, \tilde{u})} R(q, u)\right) \geq r_{c}\right\}$

where $\alpha\left(q, r_{c}\right)$ is the greatest level of uncertainty which would still be consistent with a reward no less than the critical reward, $r_{c}$, which would be demanded by the decision maker (Ben-Haim 2006). One may say that the info-gap theory strives to find the greatest decision-specific size of a possible uncertainty set that would still allow for acceptable rewards (Knoke 2011).

The mathematical concept of the info-gap theory is in fact quite straight forward (Hayes et al. 2013) and quite useful for many analyses. However, the requirement of a critical reward makes the analysis somewhat local (Sniedovich 2012). The hypothetical uncertainty set found by the info-gap analysis will most likely only be a subset of the true, but unknown, uncertainty set. The true reward (consequence) of a decision could still be outside the uncertainty set consistent with the optimal info-gap decision. Nevertheless, one might still be interested in the performance of a decision, if their true reward is outside the uncertainty set describing the neighborhood of the assumed/estimated reward. In other words: If the critical reward is not met, we might still want a relatively good performance, even under such circumstances.

To avoid considering too small uncertainty sets, our method considers sets of uncertainties of various sizes for economic return (input) coefficients of each single potential portfolio component, which form a common uncertainty space for all considered uncertainty scenarios. We demand that the maximum deviation to the best possible solution is minimized for all combinations of return coefficients included in these uncertainty spaces. However, we are not limited by demanding a fixed critical reward. This is different from the before described info-gap perspective, where uncertainty in the neighborhood of the assumed/estimated economic return would be considered.

\subsection{Application of the two different portfolio approaches to a forest management example}

\subsubsection{Data}

The calculations of the annuities, which we used for both of the optimization processes, were generated following the Roessiger et al. (2011) model. Fluctuations of the wood prices, harvesting and afforestation costs, and the risk of stand failure were simulated to generate a more or less realistic variation in possible returns. However, deviating from Roessiger et al. (2011), the yield was based on a data set published by Pretzsch et al. (2014), which was prepared for economic considerations by Hofmann (2014) (see Table 2). This data set led to 17 rotation age cohorts. In our study, regeneration costs were assumed for Norway spruce, $2000 € \mathrm{ha}^{-1}$; and European beech, $3000 €$ ha $^{-1}$. The time series for wood prices, adopted from the Bavarian state forests (Bayerisches Staatsministerium für Ernährung, Landwirtschaft und Forsten 2015), were updated for the year 2014. The adjustment of expected gross revenues to fluctuation in timber prices was achieved by multiplying a quotient with the gross revenues representing timber prices of the reference year 2014. The quotient was formed by dividing the annual main assortment prices (mid-diameter Sp 25-29 cm and $\mathrm{Be} 30$ $34 \mathrm{~cm}$ ), i.e., the weighted price considering all quality classes, by the average timber price for these assortments of the whole

Table 2 Expected exploitable wood volume in $\mathrm{m}^{3}$ per hectare (understood as roundwood without bark in cubic meters per hectare) for different age classes for Norway spruce (Sp) and European beech $(\mathrm{Be})$

\begin{tabular}{lll}
\hline Age class & $\mathrm{Sp}\left(\mathrm{m}^{3} \mathrm{ha}^{-1}\right)$ & $\mathrm{Be}\left(\mathrm{m}^{3} \mathrm{ha}^{-1}\right)$ \\
\hline 30 & 276 & \\
40 & 435 & 15 \\
50 & 558 & 125 \\
60 & 659 & 215 \\
70 & 744 & 290 \\
80 & 818 & 356 \\
90 & 883 & 414 \\
100 & 941 & 466 \\
110 & & 513 \\
120 & & 556
\end{tabular}

Volume is calculated with a growth model from Pretzsch et al. (2014) and prepared for economic analyses by Hofmann (2014) 
time series. The resulting wood price quotients, see Table 3, were then used to calculate the random deviations of the gross revenues from the reference values in year 2014 (see Table 4). With the help of a MCS with 10,000 repetitions and a bootstrapping method for the random choice of the wood price year, the means of the annuities of each rotation age cohort and the associated standard deviation, which is the measure for risk in the study, were calculated. The annuities were calculated for all 17 rotation age cohorts using a discount rate of $1 \%$. This discount rate forms a platform to start from. However, during sensitivity tests, we used alternative discount rates. The annuities and standard deviations of the different rotation age cohorts and tree species can be seen in Table 1 and were used as the input data for the stochastic and the nonstochastic optimizations. In summary, we can say that we used a completely new data set compared to Roessiger et al. (2011).

To carry out the stochastic and non-stochastic optimization of the portfolios, a large-scale solver (What's Best! 2011) from Lindo Systems, Inc. was used as an add-in to Microsoft Excel.

\subsubsection{Case study data}

For the case study, the stand area covered by spruce (Sp) may be harvested and regenerated totally or in part at the ages 30 , $40,50,60,70,80,90$, and 100 years and beech $(\mathrm{Be})$ at the ages $40,50,60,70,80,90,100,110$, and 120 years. These 17 possible rotation age cohorts all have their own average annuities and standard deviations (Table 1). With potential stand regeneration starting at age 30 years and ending at age 120 years, the approach allows a regeneration process potentially extending over $80-90$ years, which may be considered a more than sufficient period to transition from even-aged to uneven-aged management at the stand scale (e.g., Knoke and Plusczyk 2001).

The lower limit for the 17 rotation age cohorts was chosen to reflect the stand age at which the two tree species first produce marketable wood volumes: Sp 30 and $\mathrm{Be} 40$. The upper limit was set to reflect common practices in central Europe (Sp 100) and for beech (Be 120) to acknowledge that, due to mainly firewood production, the economic return does rather decrease after year 100 (Table 1). For the non-stochastic optimization, 131,072 $\left(2^{17}\right)$ different uncertainty scenarios were used and implemented as constraints. Depending on the factor $m$ to control the size of the uncertainty space, we conducted 21 robust portfolio optimizations: one for each of the different values of $m$. For the stochastic optimization, we performed 33 portfolios, beginning with an unrestricted level of risk for the whole portfolio and reducing this level step by step to the lowest achievable risk level while the annuities were always maximized for the given levels of risk. For the stochastic optimization process, the simulated correlation coefficients, depending on the portfolio shares, were used (see Table 5).
Table 3 Real wood price development between 1975 and 2014 based on the data set from the Bavarian state forest

\begin{tabular}{|c|c|c|c|c|}
\hline Year & $\begin{array}{l}\text { Norway spruce } \\
\text { wood } \\
\text { price in } € \text { per cubic } \\
\text { meter }\end{array}$ & $\begin{array}{l}\text { European beech } \\
\text { wood } \\
\text { price in } € \text { per cubic } \\
\text { meter }\end{array}$ & $\begin{array}{l}\text { Quotient } \\
\text { Sp }\end{array}$ & $\begin{array}{l}\text { Quotient } \\
\mathrm{Be}\end{array}$ \\
\hline 1975 & 43 & 43 & 0.758 & 0.662 \\
\hline 1976 & 46 & 43 & 0.798 & 0.664 \\
\hline 1977 & 50 & 50 & 0.876 & 0.766 \\
\hline 1978 & 44 & 56 & 0.768 & 0.861 \\
\hline 1979 & 44 & 60 & 0.772 & 0.925 \\
\hline 1980 & 61 & 67 & 1.077 & 1.031 \\
\hline 1981 & 52 & 73 & 0.919 & 1.121 \\
\hline 1982 & 52 & 73 & 0.913 & 1.131 \\
\hline 1983 & 48 & 73 & 0.843 & 1.118 \\
\hline 1984 & 47 & 72 & 0.815 & 1.105 \\
\hline 1985 & 57 & 72 & 1.006 & 1.107 \\
\hline 1986 & 53 & 72 & 0.927 & 1.101 \\
\hline 1987 & 57 & 72 & 1.004 & 1.109 \\
\hline 1988 & 58 & 72 & 1.009 & 1.111 \\
\hline 1989 & 66 & 74 & 1.152 & 1.140 \\
\hline 1990 & 64 & 75 & 1.114 & 1.160 \\
\hline 1991 & 36 & 54 & 0.634 & 0.827 \\
\hline 1992 & 31 & 69 & 0.538 & 1.068 \\
\hline 1993 & 40 & 71 & 0.698 & 1.090 \\
\hline 1994 & 53 & 68 & 0.935 & 1.052 \\
\hline 1995 & 56 & 76 & 0.987 & 1.166 \\
\hline 1996 & 51 & 72 & 0.896 & 1.103 \\
\hline 1997 & 52 & 69 & 0.915 & 1.057 \\
\hline 1998 & 58 & 69 & 1.017 & 1.069 \\
\hline 1999 & 61 & 72 & 1.063 & 1.105 \\
\hline 2000 & 52 & 74 & 0.911 & 1.133 \\
\hline 2001 & 58 & 72 & 1.023 & 1.114 \\
\hline 2002 & 58 & 66 & 1.014 & 1.020 \\
\hline 2003 & 57 & 63 & 0.996 & 0.965 \\
\hline 2004 & 53 & 60 & 0.929 & 0.924 \\
\hline 2005 & 59 & 53 & 1.032 & 0.814 \\
\hline 2006 & 63 & 52 & 1.106 & 0.807 \\
\hline 2007 & 67 & 58 & 1.182 & 0.892 \\
\hline 2008 & 62 & 65 & 1.092 & 1.001 \\
\hline 2009 & 63 & 60 & 1.105 & 0.925 \\
\hline 2010 & 69 & 54 & 1.201 & 0.829 \\
\hline 2011 & 79 & 60 & 1.382 & 0.931 \\
\hline 2012 & 85 & 66 & 1.489 & 1.014 \\
\hline 2013 & 87 & 64 & 1.531 & 0.990 \\
\hline 2014 & 90 & 64 & 1.574 & 0.993 \\
\hline
\end{tabular}

Prices are weighted by different quality assortments from the main assortments for spruce $(\mathrm{Sp})(25-29 \mathrm{~cm})$ and for beech $(\mathrm{Be})(30-34 \mathrm{~cm})$ for each year. The quotient is calculated by dividing these mixed annual prices of $\mathrm{Sp}$ and $\mathrm{Be}$ of each year by the means of $\mathrm{Sp}$ and Be price over the whole time range 
Table 4 Wood prices in $€$ per cubic meter (roundwood without bark) for Norway spruce and European beech have been obtained through prices weighted by assortment shares for the year 2014

\begin{tabular}{lll}
\hline Diameter ranges/class $(\mathrm{cm})$ & Norway spruce & European beech \\
\hline $10-14$ & 56 & 63 \\
$15-19$ & 74 & 63 \\
$20-24$ & 83 & 63 \\
$25-29$ & 90 & 63 \\
$30-34$ & 91 & 56 \\
$35-39$ & 92 & 64 \\
$40-49$ & 92 & 73 \\
$50-59$ & 93 & 83 \\
$\geq 60$ & 93 & 89 \\
Industrial wood & 55 & 48 \\
\hline
\end{tabular}

To compare the portfolios obtained from stochastic and non-stochastic optimization, we computed the expected economic return and standard deviation for the non-stochastic portfolios assuming a "mean-variance world". Annuities and standard deviations of these non-stochastic portfolios were then compared with corresponding portfolios from the efficient frontier, which had the same standard deviation as the non-stochastic portfolio.

\section{Results}

The portfolios obtained from non-stochastic optimization were in general less variable compared to those resulting from stochastic optimization. That means that the non-stochastic portfolios corresponded only to a quite limited range of standard deviations and average economic return. While stochastic optimization suggested efficient portfolios over a range of standard deviations from \pm 10 (average economic return -60 Euro $\mathrm{ha}^{-1}$ year $^{-1}$ ) to \pm 168 (average economic return 400 Euro ha $^{-1}$ year $^{-1}$ ), non-stochastic optimization suggested portfolios corresponding to \pm 83 (average economic return 292 Euro $\mathrm{ha}^{-1}$ year $^{-1}$ ) to \pm 115 (economic return 374 Euro $\mathrm{ha}^{-1}$ year $^{-1}$ ). For better comparison of the results of the optimization approaches, we focused on the portfolios associated with identical standard deviations. Standard deviations resulted from the uncertainty space sizes one to three times the standard deviation.

\subsection{Comparison of the results of the optimization approaches}

The results consist of a series of stochastic and non-stochastic forest management portfolios, displaying the shares of the rotation age cohorts across different levels of accepted/ considered economic risks (see Figs. 1 and 2). In general,

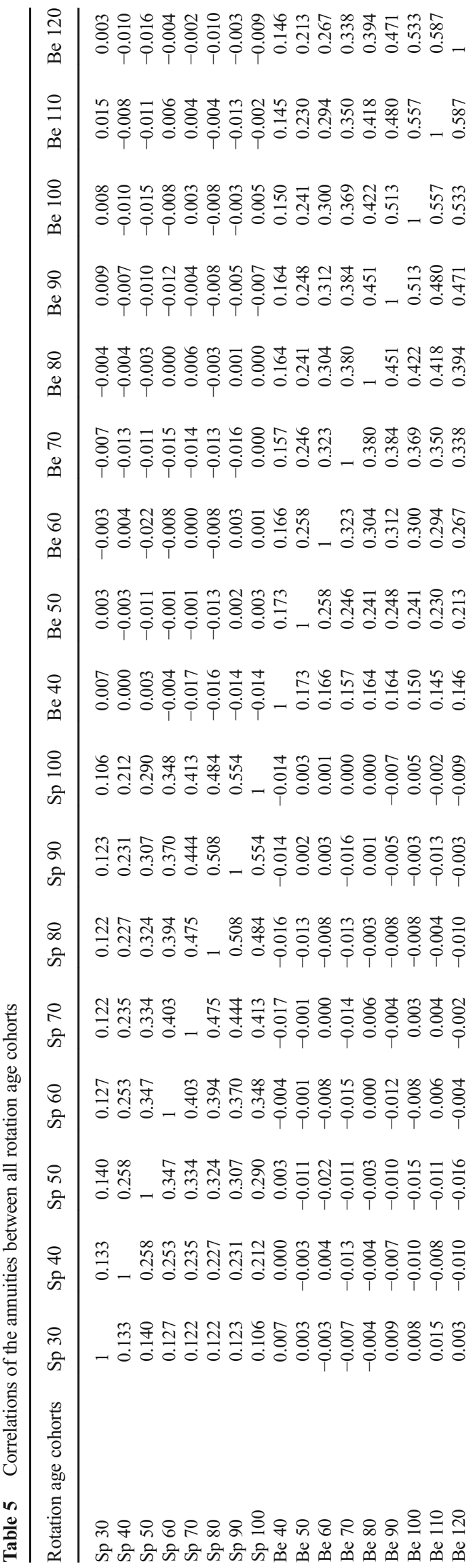


the mean-variance optimized portfolio becomes less diverse as the level of accepted economic risk increases. The minimum risk among the here compared portfolios was a standard deviation of 83 , at which point 10 rotation age cohorts $(8 \mathrm{Sp}$ and $2 \mathrm{Be}$ ) were included in the portfolio (Fig. 1). At this level of the economic standard deviation, still $91 \%$ of the stand's area were covered by Norway spruce. The share of $9 \%$ of European beech decreased with a higher tolerated economic risk until it disappeared completely $\left(S_{A}=92\right)$. Land initially allocated to a range of various rotation age cohorts of Norway spruce narrowed as accepted risk increased and finally only rotation age cohorts for Norway spruce with harvesting at 40 , $50,60,70$, and 80 remained. The value of the objective function changed from 299 to $384 € \mathrm{ha}^{-1}$ year $^{-1}$ as the level of accepted risk rose from 83 to the maximum of 115 for the rotation age cohort of Norway spruce 40, 50,60,70, and 80 .

The non-stochastic optimization approach integrated maximally 13 rotation age cohorts, if the uncertainty space was very large, as shown in the left column of Fig. 2. The resulting portfolios were generally more diverse, and rotation age cohorts were distributed more equally compared with those obtained from stochastic optimization, if portfolios with identical standard deviations were compared. For example, for a standard deviation of \pm 105 , the non-stochastic portfolio contained seven rotation age cohorts, all comprising between 11 and $17 \%$ of the stand area, while the stochastic portfolio included also seven rotation age cohorts for this standard deviation, however, covering between 2 and $25 \%$ of the stand area. The land allocations within these non-stochastic portfolios were thus distributed more evenly for changing uncertainty levels compared to those from stochastic optimization. Spruce clearly dominated the portfolios across all levels of uncertainty. Beech only became part of the portfolio for standard deviation lower than \pm 92 , thus using $u_{s i}=2.8^{*} s_{i}$ or higher. The shares of Sp 100, Sp 90, Sp 80, and Sp 40 remained relatively stable for a range of standard deviations between \pm 83 and \pm 106 (which is related to $1.8^{*} s_{i} \leq u_{s i} \leq 3.0^{*} s_{i}$ ) and showed allocated land percentage fractions between 9 and $15 \%$. Sp 50 in general is very stable over the whole range of changing uncertainty spaces: it rises from $12 \%$ for the lowest standard deviation to $24 \%$ of stand area allocated to this rotation age cohort for the highest uncertainty. The percentage fraction of rotation age cohort Sp 60 decreased most with increasing size of the uncertainty spaces. For the smallest uncertainty factor considered here (standard deviation of \pm 115 ), still six rotation age cohorts were included in the portfolio ( $\mathrm{Sp}$ 40-Sp 90). Spruce rotation age cohort harvested with 30 years were only included in the portfolios under a higher uncertainty factor $m$ (Fig. 2). Across the different risk levels, the nonstochastic portfolios provided an average annual return between $292 €$ and $374 € \mathrm{ha}^{-1}$ year $^{-1}$. If the uncertainty factor was further reduced (reflecting a less cautious perspective), the non-stochastic optimization portfolio becomes less diverse, with only slightly higher annuities, but increasing standard deviation. In summary, we may conclude that nonstochastic portfolios become more diverse, if decision makers expect increasing uncertainties, represented by larger sizes of uncertainty spaces considered. This means that considering rather large uncertainties is supportive to uneven-aged forestry strategies. If forest owners would rather expect uncertainties of limited size, they would rather tend to an age class system, although still with a diversified harvesting spread over several periods.

The difference in the composition of forest portfolios calculated by the stochastic and robust optimization approach can be seen in Figs. 1 and 2. As an example, we look at the portfolios for a standard deviation of \pm 83 (left-hand column) and \pm 115 (right-hand column). The robust portfolios are more diverse than the stochastic ones. For cautious decision makers, expecting high uncertainty and thus using a high uncertainty factor of $u_{s i}$ equal to 3 times the standard deviation, this portfolio consists of 13 different rotation age cohorts ( 8 spruce and 5 beech shares), while the corresponding stochastic portfolio includes 10 rotation age cohorts. The stochastic portfolio only

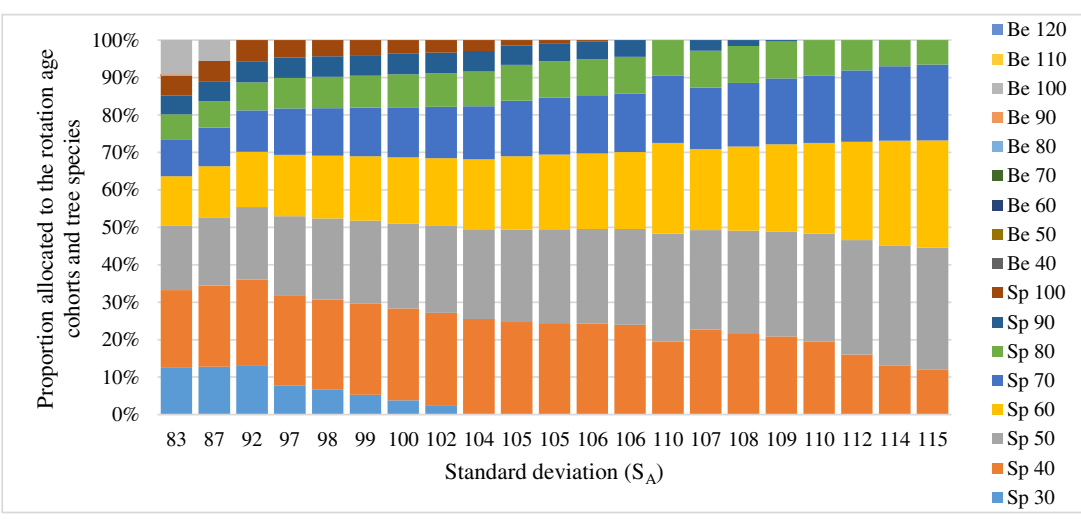

Fig. 1 Forest management portfolios, composed of Norway spruce $(S p)$ and European beech $(B e)$, forming the efficient frontier in a meanvariance optimization. Provided are maximal average annual payments for a certain standard deviation $\left(S_{A}\right)$. Standard deviations correspond to the uncertainty space sizes from the non-stochastic optimization. As some of the uncertainty space sizes result in very similar standard deviation, rounded standard deviations occur as duplicates 


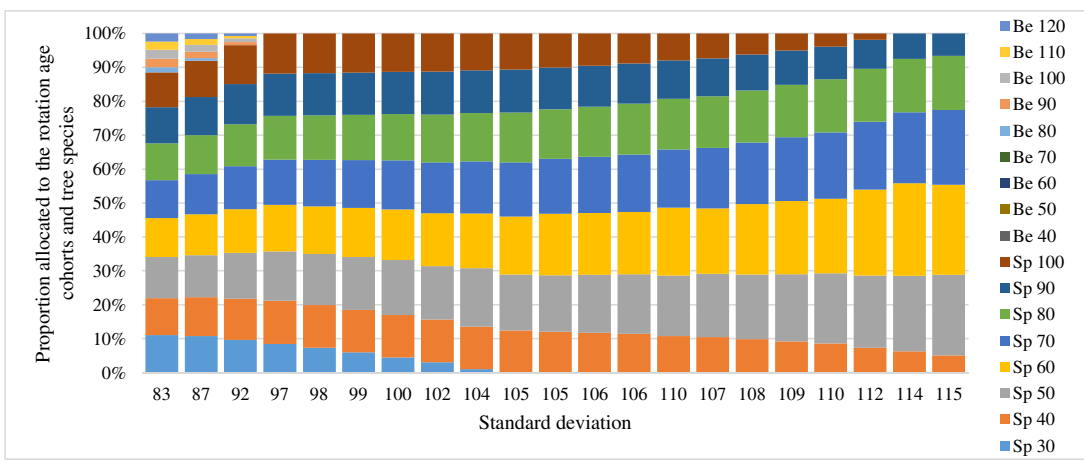

Fig. 2 Forest management portfolios, composed of Norway spruce ( $S p)$ and European beech $(\mathrm{Be})$, derived for large deviations considered (left $m=3.0$, corresponds to a standard deviation of 83) and smaller deviations (right $m=1.0$, corresponds to a standard deviation of 115) with their corresponding uncertainty sets, expressed as the standard deviation. Represented are portfolios for all uncertainty space sizes between $1.0 \leq$ $m \leq 3.0$ increasing in 0.1 steps; thus, each column shows a different uncertainty space shows two beech rotation age cohorts $(\mathrm{Be} 90$ and $\mathrm{Be} 100)$ for a standard deviation of \pm 83 , while the non-stochastic portfolio comprises five beech rotation age cohorts for this standard deviation. Even if the five beech rotation age cohorts together have only about $11 \%$ allocated land, the spruce rotation age cohorts are distributed rather regularly in this conservative non-stochastic optimized portfolio.

We also considered only downside deviation for the nonstochastic optimization approach. Figure 3 depicts the following consequences: for an uncertainty space of 1 times the standard deviation, thus a high level of risk acceptance, the standard deviation (122), and annuity ( $386 € \mathrm{ha}^{-1} \mathrm{year}^{-1}$ ) are slightly higher than under the double-sided optimization; however, there are two rotation age cohorts less included in the portfolio. For the high risk aversion, accordingly, in an uncertainty space set up with three times the standard deviation, the differences are even more significant. Just one European beech rotation age cohort (Be 100) appears in the portfolio, however, with a percentage fraction area of almost $40 \%$ (see Fig. 3). Consequently the standard deviation (64) and the annuity ( $234 € \mathrm{ha}^{-1}$ year $\left.^{-1}\right)$ are clearly lower for considering one-sided deviation. The median uncertainty space (two times the standard deviation) resulted in quite similar percentage fraction areas compared to the two-sided optimization. The standard deviation (108) and the annuity (363 $€$ ha $^{-1}$ year $^{-1}$ ) only show slight differences to the portfolio optimized with the double-sided deviation.

\subsection{Performance of robust portfolios in a mean-variance context}

Figures 1 and 2 demonstrate the differences in allocated portfolio weights (shares of our rotation age cohorts) between the two optimization approaches. Here we investigated the size of the losses that could potentially occur when using nonstochastic approaches. For each level of standard deviation associated with a non-stochastic portfolio, we calculated the (stochastic) portfolio that maximizes the expected return and hence is a member of the efficient frontier. Figure 4 compares the efficient frontier formed by the mean-variance optimized portfolios with the portfolios from the robust optimization $(1.0 \leq m \leq 3.0)$. Thus, the annuities of the non-stochastic optimization were compared to the highest possible annuities (from the stochastic optimization) for the same level of risk.

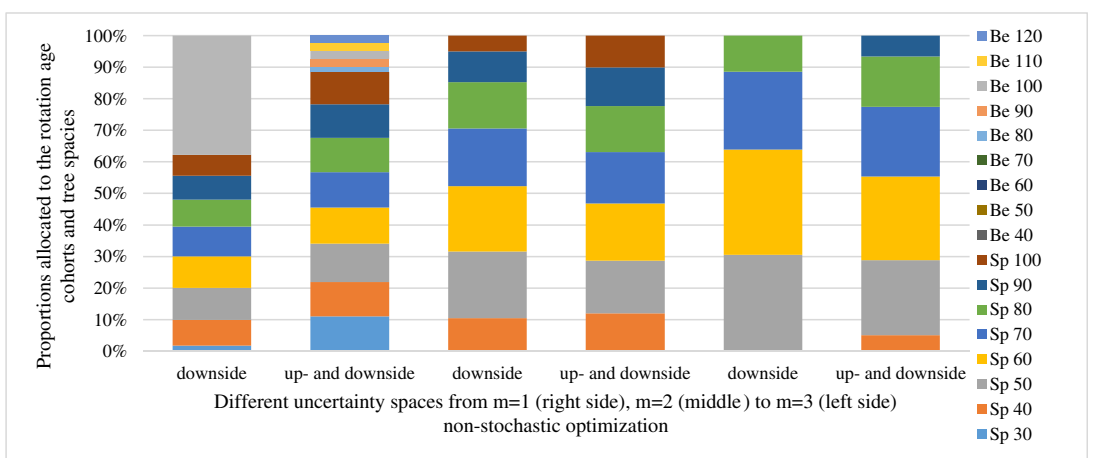

Fig. 3 Comparison of the percentage fractions of rotation age cohorts for non-stochastic optimization approaches with one-side (downside) deviation to double-side (downside and upside) deviation. Compared are the uncertainty spaces one, two and three times the standard deviation, which result in standard deviations of 83, 97, and 115 from the left to the right 
Fig. 4 Economic performance of robust portfolios (obtained from a non-stochastic optimization) compared to the efficient frontier of a mean-variance optimization

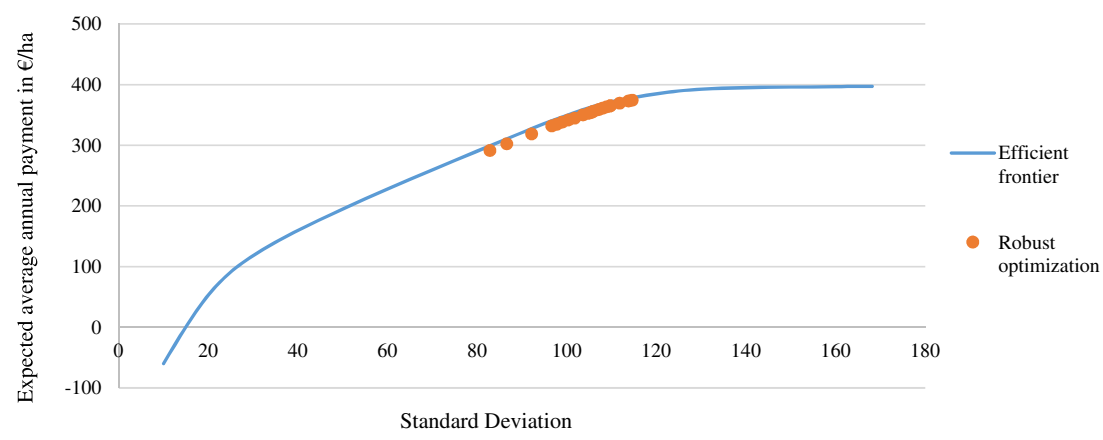

The robust optimization portfolios achieved slightly lower average economic returns than those from mean-variance optimization. The smallest difference, however, was just $1 \%$, representing a loss of $3.94 € \mathrm{ha}^{-1}$ year ${ }^{-1}$ for an uncertainty space of $m=1.0$ times the standard deviation. The highest potential economic loss caused by a non-stochastic optimization portfolio still amounted to under $3 \%$. This was the case at a level of uncertainty of $u_{s i}$ between $2.7^{*} s_{i}$ (standard deviation of \pm 97 ) and $3.0^{*} s_{i}$ (standard deviation of \pm 83 ). This corresponded to a loss of around $8-9 €$ ha $^{-1}$ year $^{-1}$ compared to the efficient portfolio derived from the mean-variance approach. The greater the considered uncertainty spaces, not only the higher are the possible economic losses of a non-stochastic approach, but also the more diverse are the resulting portfolios.

\subsection{Sensitivity analysis of the discount rate}

Sensitivity analysis for a discount rate of $2 \%$ resulted, in general, in lower annuities for Norway spruce and European beech. While Norway spruce rotation age cohorts attained average annuities between 108 and 272 $€$ ha $^{-1}$ year $^{-1}$ with Sp 30 as the lowest and Sp 50 as the highest, all European beech rotation age cohort annuities were negative. The rotation age cohort Be 90 with an average annuity of $-15 € \mathrm{ha}^{-1}$ year $^{-1}$ was even the best option and $\mathrm{Be} 40\left(-153 € \mathrm{ha}^{-1} \mathrm{year}^{-1}\right)$ the worst. Within the rotation age cohorts calculated with a discount rate of $1 \%$, only $\mathrm{Be} 40-\mathrm{Be} 60$ had negative average annuities (see Table 1). Besides the lower annuities, also the rotation age cohort with the highest average annuities changed to the lower rotation age cohort in each case for the higher discount rate of $2 \%$. As a consequence for the portfolios, the annuities of the portfolios decreased for both stochastic and non-stochastic optimization. In addition, the European beech rotation age cohorts were completely excluded from the portfolios because of the low and even negative rotation age cohort annuities. The general structure of the non-stochastic portfolios, however, hardly changed.

\section{Discussion and conclusion}

The results show that non-stochastic portfolio optimization may support forest management decisions successfully, even when various rotation age cohorts are part of the optimization problem. Compared with a classical stochastic optimization, which needs a comprehensive set of input data (particularly covariances between all considered portfolio elements), we could show that the less data demanding non-stochastic optimization achieved quite excellent results, which underline the significance of this new approach when data is scarce. In contrast to the approach used by Knoke et al. (2015) for optimizing agricultural croplands, our approach considered various rotation age cohorts and with this various periods, through which we extended the agricultural study by Knoke et al. (2015).

Portfolios calculated with the non-stochastic approach showed only slightly lower average annual return compared to portfolios from the efficient frontier. The economic losses lie between 1 and $3 \%$, but these portfolios are relatively diverse, including between six and 13 rotation age cohorts. The basic results obtained are comparable to those of Knoke et al. (2015). The non-stochastic portfolios of both studies include various assets and change only moderately under changing levels of assumed risk. Economic losses in the land-use study from Knoke et al. (2015) were, with a difference of 2 to $4 \%$ compared to the efficient frontier, slightly higher than those of the present study. Comparing the nonstochastic portfolios with those forming the efficient frontier and thus using the standard deviation as the reference can be seen critically. However, even if this method assumes that the results from the stochastic portfolio optimization are seen as the absolute maximum, it is a straightforward way to compare economic performance given an identical uncertainty, even if the uncertainty measure has some weaknesses.

Our paper used expected growth data from Pretzsch et al. (2014) for Norway spruce and European beech. The portfolios resulting from the stochastic optimization approach with this updated data compared to the portfolios obtained by Roessiger et al. (2011), calculated with the same model but different data, showed basically the same pattern of decreasing diversity with increasing risk acceptance. Due to the high wood 
prices in the year 2014, our reference year for calculating the wood price, the general price level is significantly higher and consequently the annuities and the standard deviations of the single rotation age cohorts were also higher. This led to a change in the rotation age cohort with the maximum average return: in the present study, $\mathrm{Sp} 60$ is the rotation age cohort for the highest expected return, while this was Sp 80 given the data used by Roessiger et al. (2011). The fact that our study did not integrate returns from thinning operations did not strongly affect the composition of the portfolios, as a comparison to the results of Roessiger et al. (2011) shows. These earlier net revenues from thinnings could, however, positively affect the shares of European beech in the non-stochastic portfolios because of the advantageous low standard deviation of the beech rotation age cohorts. Thinnings could also lead to increased proportions of European beech if returns from thinnings, such as for fuel wood, would increase the expected return. Results of the optimizations based on updated data suggest that the reference year and length of the time series for wood prices are more important for the stochastic optimization than for the non-stochastic approach. For comparison, we also calculated the non-stochastic portfolios with the previous data set, used by Roessiger et al. (2011). The general findings that stochastic portfolios showed strong changes in their composition and an increasing share of beech under decreasing levels of accepted risk were more evenly distributed within spruce were not altered, even for the here applied $1 \%$ discount rate. One consequence, however, was the high annuities for spruce. However, using a discount rate of $2 \%$, beech did not reach positive annuities as we considered investment costs of establishing the plantation, contrary to the study of Roessiger et al. (2011). Beech was thus completely excluded from the non-stochastic portfolios under all risk levels for an increase in the interest rate. However, the structure of spruce rotation age cohorts of the non-stochastic portfolios hardly changed when using an interest rate of $2 \%$.

The appropriate multiplication factor for the standard deviation to construct uncertainty spaces should be investigated in more detail. The size of the uncertainty space should relate to the forest manager's degree of caution, which could be approximated by his/her degree of risk aversion. Holt and Laury (2002) investigated the impact of the degree of risk aversion on decision-making with the example of a simple lottery. An adequate portfolio for each level of risk aversion can therefore serve as a management support tool in forest decision-making. However, the appropriate multiplication factor and consequently the size of the uncertainty space within the non-stochastic approach do not influence the composition of the portfolio as much as the changing risk levels in the stochastic approach. Thus, with a moderate size of the uncertainty space of 2 times the standard deviation, stable portfolios can be achieved for further planning.
A related point is the shape of the uncertainty space. For greater precision, the shape of the uncertainty space could be changed to conic, polyhedral, convex, elliptical, or other forms (Bertsimas and Brown 2009). Within these multidimensional spaces, we assume that each combination of return coefficients is equally likely. Changes in the shape of the uncertainty spaces could reflect more likely combinations of return coefficients. However, these alternative shapes or multidimensional spaces demand more information on correlations between the economic returns and complicate the calculations (Ben-Tal et al. 2009). For a practical linear programming problem, the square shape used in this paper is useful, but modifying this shape could help map the distribution of possible economic returns more exactly, resulting in a more precise model. Approaches to achieve this can, for example, be seen in the studies of Goldfarb and Iyengar (2003) and Ben-Tal and Nemirovski (2002). Regardless, the economic losses of the robust nonstochastic model compared with the efficient frontier are, despite the simple shape of the uncertainty factor sets, only small. The opportunity to use linear programming, which is made possible by ignoring covariances, did not imply any great disadvantages in the performance of the non-stochastic model.

The non-stochastic model is, in its present form, not feasible for extremely high numbers of constraints, because of technical limitations of the software used, Microsoft Excel, and the exponentially rising number of scenarios with increasing number of options considered as portfolio components. Consequently, we were limited to 17 rotation age cohorts to solve the linear problem because all 131,072 constraints have to be solved simultaneously. For example, with 18 options for the optimization process, the working memory of Microsoft Excel 2010 cannot perform the calculations. Therefore, limitations for the optimization process in this study were technical in nature. For this study, 17 options were sufficient; however, it would be preferable in future optimizations to relax this restriction by using options to reduce the number of uncertainty scenarios that have to be considered. This is especially the case if further studies focus on single-tree optimization.

The almost complete exclusion of beech from the portfolio composition by non-stochastic optimization was not as surprising as it may have seemed at the first glance. Because of the very low economic return for European beech only extremely risk-averse decision makers would choose beech rotation age cohorts from a purely economic point of view. In the non-stochastic model, European beech was only part of portfolios with very large uncertainty spaces and thus low standard deviations of \pm 83 to \pm 92 . However, only when disregarding interactions between tree species (Griess and Knoke 2013; Knoke and Seifert 2008; Liang et al. 2016; Pretzsch et al. 2010), climatic change (Neuner et al. 2015), and other aspects, such as biodiversity (Gamfeldt et al. 2013) or multiple ecosystem services (Knoke et al. 2016), different rotation age cohorts of pure Norway spruce appear appropriate for achieving sustainable forest stands. 
As mentioned in Sect. 1, the practical application example of the new approach refers to an even-aged forest stand, which will be transformed into an uneven-aged mixed forest, if uncertainties are important. The results have practical relevance particularly for forest owners with only small properties. Here, risks and uncertainties are very important, because very low economic performance cannot be compensated by other parts of a larger forest property. The results obtained may be used for consultancy of such smaller forest owners. They show that starting quite early with the regeneration of a forest stand and then carrying out many regeneration harvests of similar sizes over several decades may be effective in buffering against uncertainties. In the context of climate change and higher economic risks of even-aged spruce monocultures (Neuner and Knoke 2017) which affects especially small-scale forest owners, who at least in Germany are used to prefer rather pure and even-aged Norway spruce stands (Roessiger et al. 2011), such management options that provide frequent and stable economic returns are quite attractive. However, the model shall in the future research also be transferred to rotation age cohorts referring to diameter ranges and thus be adaptable to already existing uneven-aged forest stands. One possible approach for this transformation could be a matrix model approach inspired by Roessiger et al. (2016). The number of options, however, will clearly play a key role in the feasibility of the combination of these techniques.

Especially for these small-scale forest owners, a further advantage of applying an uneven-aged mixed forest management system is the high flexibility towards timber price fluctuations and assortment harvesting. Thus, harvest intensity can be adjusted to current market states. Prestemon and Wear (2000) found out that owners are sensitive to fluctuating prices particularly if the changes are short-term fluctuations. Knoke and Wurm (2006) stated that especially for European beech, a flexible harvesting is attractive. This could be useful when more stable uneven-aged mixed forests (including beech) resist to calamities, and thus, forest owners can bridge drops in wood prices. Additionally, forest owners of mixed uneven-aged forests can decide on harvesting certain assortments (Brazee and Mendelsohn 1988; Prestemon and Wear 2000). If pulpwood prices are high, rotation age cohorts like Sp30 or Sp40 can be harvested, whereas if the demand for lumber is highest, he/she can decide to cut Sp 80, for example.

To conclude, this study demonstrates the high-performance of a robust optimization approach for forest management planning. Results from the optimization with this model are promising, especially for optimizations with scarce data. However, further research is needed to reduce the number of constraints/ uncertainty scenarios, to modify the size and shape of the uncertainty spaces, and to integrate ecological effects among tree species and other biodiversity aspects into management decisions.
Acknowledgements We are grateful to "Deutsche Forschungsgemeinschaft" (DFG) for financial support of the study (KN 586/11-1, KN-586/7-2) and to all supporting colleges from the Institute of Forest Management at TU München. We also thank the Bavarian State Ministry for Nutrition, Agriculture, and Forestry for permanent support of the project W 07 "Long-term experimental plots for forest growth and yield research" (\#7831-20400-2012) which provided the data for this study. Furthermore, we thank Elizabeth Gosling and Chelsea Jones for the language editing.

\section{Compliance with ethical standards}

Funding The study was funded by "Deutsche Forschungsgemeinschaft" (DFG) (KN 586/11-1).

Open Access This article is distributed under the terms of the Creative Commons Attribution 4.0 International License (http:// creativecommons.org/licenses/by/4.0/), which permits unrestricted use, distribution, and reproduction in any medium, provided you give appropriate credit to the original author(s) and the source, provide a link to the Creative Commons license, and indicate if changes were made.

\section{References}

Abson DJ, Fraser EDG, Benton TG (2013) Landscape diversity and the resilience of agricultural returns: a portfolio analysis of land-use patterns and economic returns from lowland agriculture. Agric Food Secur 2(1):2. doi:10.1186/2048-7010-2-2

Albadvi A, Koosha H (2011) A robust optimization approach to allocation of marketing budgets. Manag Decis 49(4):601-621. doi:10. $1108 / 00251741111126512$

Bayerisches Staatsministerium für Ernährung, Landwirtschaft und Forsten (2015) Holzpreisstatistik für die Jayhre 1975-2014, München

Beinhofer B (2009) Zur Anwendung der Portfoliotheorie in der Forstwissenschaft: Finanzielle Optimierungsansätze zur Bewertung von Diversifikationseffenkten. Dissertation, Technische Universität München

Ben-Haim Y (2006) Info-gap decision theory: decisions under severe uncertainty, 2nd edn. Academic, Oxford

Ben-Tal A, Nemirovski A (2000) Robust solutions of linear programming problems contaminated with uncertain data. Math Program 88(3): 411-424. doi:10.1007/PL00011380

Ben-Tal A, Nemirovski A (2002) Robust optimization-methodology and applications. Math Program 92(3):453-480. doi:10.1007/ s101070100286

Ben-Tal A, El Ghaoui L, Nemirovskiǐ AS (2009) Robust optimization. Princeton series in applied mathematics. Princeton University Press, Princeton

Bertsimas D, Brown DB (2009) Constructing uncertainty sets for robust linear optimization. Oper Res 57(6):1483-1495. doi:10.1287/opre. 1080.0646

Brazee R, Mendelsohn R (1988) Timber harvesting with fluctuating prices. For Sci 34(2):359-372(14)

Ciancio O, Iovino F, Menguzzato G, Nicolaci A, Nocentini S (2006) Structure and growth of a small group selection forest of calabrian pine in Southern Italy: a hypothesis for continuous cover forestry based on traditional silviculture. For Ecol Manag 224(3):229-234. doi:10.1016/j.foreco.2005.12.057

Coumou D, Rahmstorf S (2012) A decade of weather extremes. Nat Clim Chang. doi:10.1038/nclimate1452 
Davies O, Haufe J, Pommerening A (2008) Silvicultural principles of continuous cover forestry: a guide to best practice. Forestry Commission Wales, England

Dragicevic A, Lobianco A, Leblois A (2016) Forest planning and productivity-risk trade-off through the Markowitz mean-variance model. Forest Policy Econ 64:25-34. doi:10.1016/j.forpol.2015. 12.010

Edwards SF, Link JS, Rountree BP (2004) Portfolio management of wild fish stocks. Ecol Econ 49(3):317-329. doi:10.1016/j.ecolecon.2004. 04.002

Figge F (2004) Bio-folio: applying portfolio theory to biodiversity. Biodivers Conserv 13(4):827-849. doi:10.1023/B:BIOC. 0000011729.93889 .34

Gabrel V, Murat C, Thiele A (2014) Recent advances in robust optimization: an overview. Eur J Oper Res 235(3):471-483. doi:10.1016/j. ejor.2013.09.036

Gamfeldt L, Snäll T, Bagchi R, Jonsson M, Gustafsson L, Kjellander P, Ruiz-Jaen MC, Fröberg M, Stendahl J, Philipson CD, Mikusiński G, Andersson E, Westerlund B, Andrén H, Moberg F, Moen J, Bengtsson J (2013) Higher levels of multiple ecosystem services are found in forests with more tree species. Nat Commun 4:1340. doi: $10.1038 /$ ncomms 2328

Goldfarb D, Iyengar G (2003) Robust portfolio selection problems. Math Oper Res 28(1):1-38. doi:10.1287/moor.28.1.1.14260

Griess VC, Knoke T (2013) Bioeconomic modeling of mixed Norway spruce-European beech stands: economic consequences of considering ecological effects. Eur J For Res 132(3):511-522. doi:10. 1007/s10342-013-0692-3

Hahn WA, Härtl F, Irland LC, Kohler C, Moshammer R, Knoke T (2014) Financially optimized management planning under risk aversion results in even-flow sustained timber yield. Forest Policy Econ 42: 30-41. doi:10.1016/j.forpol.2014.02.002

Hanewinkel M, Cullmann DA, Schelhaas M-J, Nabuurs G-J, Zimmermann NE (2012) Climate change may cause severe loss in the economic value of European forest land. Nat Clim Chang 3(3): 203-207. doi:10.1038/nclimate1687

Härtl FH, Barka I, Hahn WA, Hlásny T, Irauschek F, Knoke T, Lexer MJ, Griess VC (2016) Multifunctionality in European mountain forests - an optimization under changing climatic conditions. Can J For Res 46(2):163-171. doi:10.1139/cjfr-2015-0264

Hayes KR, Barry SC, Hosack GR, Peters GW, Freckleton R (2013) Severe uncertainty and info-gap decision theory. Methods Ecol Evol 4(7):601-611. doi:10.1111/2041-210X.12046

Hildebrandt P, Knoke T (2011) Investment decisions under uncertainty - a methodological review on forest science studies. Forest Policy Econ 13(1):1-15. doi:10.1016/j.forpol.2010.09. 001

Hofmann M (2014) Die finanzielle Umtriebszeit von Fichte und Buche in Mitteleuropa: Eine Optimierung unter Berücksichtigung von Waldwachstumstrends. Master Thesis, Technische Universität München

Holt CA, Laury SK (2002) Risk aversion and incentive effects. American economic review

Huth F, Wagner S (2013) Ökosystemleistungen von Dauerwäldern —eine aktuelle Analyse des Waldbaus. Schweiz Z Forstwes 164(2):27-36. doi:10.3188/szf.2013.0027

IPPC (2014) Climate Change 2014: Synthesis Report. Contribution of Working Groups I, II and III to the Fifth Assessment Report of the Intergovernmental Panel on Climate Change [Core Writing Team, Pachauri, RK; Meyer, LA (eds.). IPPC, Geneva, Switzerland, $151 \mathrm{pp}$.

Kangas AS, Kangas J (2004) Probability, possibility and evidence: approaches to consider risk and uncertainty in forestry decision analysis. Forest Policy Econ 6(2):169-188. doi:10.1016/ S1389-9341(02)00083-7
Kangas A, Kangas J, Kurttila M (2008) Decision support for forest management. Managing forest ecosystems, vol 16. Springer Science + Business Media B.V, Dordrecht

Knoke T (2009) Zur finanziellen Attraktivität von Dauerwaldwirtschaft und Überführung: eine Literaturanalyse $\mid$ On the financial attractiveness of continuous cover forest management and transformation: a review. Swiss For J 160(6):152-161. doi:10.3188/szf.2009.0152

Knoke T (2011) Book review: Yakov Ben-Haim, info-gap economics: an operational introduction. Ecol Econ 70(3):567-568. doi:10.1016/j. ecolecon.2010.09.018

Knoke T, Plusczyk N (2001) On economic consequences of transformation of a spruce (Picea abies (L.) karst.) dominated stand from regular into irregular age structure. For Ecol Manag 151(1-3):163-179. doi:10.1016/S0378-1127(00)00706-4

Knoke T, Seifert T (2008) Integrating selected ecological effects of mixed European beech-Norway spruce stands in bioeconomic modelling. Ecol Model 210(4):487-498. doi:10.1016/j.ecolmodel.2007.08.011

Knoke T, Wurm J (2006) Mixed forests and a flexible harvest policy: a problem for conventional risk analysis? Eur J For Res 125(3):303315. doi:10.1007/s10342-006-0119-5

Knoke T, Calvas B, Moreno SO, Onyekwelu JC, Griess VC (2013) Food production and climate protection - what abandoned lands can do to preserve natural forests. Glob Environ Chang 23(5):1064-1072. doi: 10.1016/j.gloenvcha.2013.07.004

Knoke T, Paul C, Härtl F, Castro LM, Calvas B, Hildebrandt P (2015) Optimizing agricultural land-use portfolios with scarce data - a nonstochastic model. Ecol Econ 120:250-259. doi:10.1016/j.ecolecon. 2015.10.021

Knoke T, Paul C, Hildebrandt P, Calvas B, Castro LM, Hartl F, Dollerer M, Hamer U, Windhorst D, Wiersma YF, Curatola Fernandez GF, Obermeier WA, Adams J, Breuer L, Mosandl R, Beck E, Weber M, Stimm B, Haber W, Furst C, Bendix J (2016) Compositional diversity of rehabilitated tropical lands supports multiple ecosystem services and buffers uncertainties. Nat Commun 7:11877. doi:10.1038/ ncomms 11877

Liang J, Crowther TW, Picard N, Wiser S, Zhou M, Alberti G, Schulze ED, McGuire AD, Bozzato F, Pretzsch H, de Miguel S, Paquette A, Herault B, Scherer-Lorenzen M, Barrett CB, Glick HB, Hengeveld GM, Nabuurs G-J, Pfautsch S, Viana H, Vibrans AC, Ammer C, Schall P, Verbyla D, Tchebakova N, Fischer M, Watson JV, HYH C, Lei X, Schelhaas M-J, Lu H, Gianelle D, Parfenova EI, Salas C, Lee E, Lee B, Kim HS, Bruelheide H, Coomes DA, Piotto D, Sunderland T, Schmid B, Gourlet-Fleury S, Sonke B, Tavani R, Zhu J, Brandl S, Vayreda J, Kitahara F, Searle EB, Neldner VJ, Ngugi MR, Baraloto C, Frizzera L, Balazy R, Oleksyn J, ZawilaNiedzwiecki T, Bouriaud O, Bussotti F, Finer L, Jaroszewicz B, Jucker T, Valladares F, Jagodzinski AM, Peri PL, Gonmadje C, Marthy W, O'Brien T, Martin EH, Marshall AR, Rovero F, Bitariho R, Niklaus PA, Alvarez-Loayza P, Chamuya N, Valencia R, Mortier F, Wortel V, Engone-Obiang NL, Ferreira LV, Odeke DE, Vasquez RM, Lewis SL, Reich PB (2016) Positive biodiversityproductivity relationship predominant in global forests. Science 354(6309). doi:10.1126/science.aaf8957

Lin X, Janak SL, Floudas CA (2004) A new robust optimization approach for scheduling under uncertainty. Comput Chem Eng 28(6-7): 1069-1085. doi:10.1016/j.compchemeng.2003.09.020

Lindo Systems, Inc. (2010) What's Best! Version 11.0 User's Manual, Lindo Systems, Inc., Chicago

Markowitz HM (1952) Portfolio selection. J Financ 7(1):77-91. doi:10. 1111/j.1540-6261.1952.tb01525.x

Markowitz HM (2010) Portfolio theory: as I still see it. Annu Rev Financ Econ 2(1):1-23. doi:10.1146/annurev-financial-011110-134602

Mendoza GA, Sprouse W (1989) Forest planning and decision making under fuzzy environments: an overview and illustration. For Sci 35(2):481-502 
Neuner S, Knoke T (2017) Economic consequences of altered survival of mixed or pure Norway spruce under a dryer and warmer climate. Clim Chang 140(3-4):519-531. doi:10.1007/s10584-016-1891-y

Neuner S, Beinhofer B, Knoke T (2013) The optimal tree species composition for a private forest enterprise - applying the theory of portfolio selection. Scand J For Res 28(1):38-48. doi:10.1080/ 02827581.2012 .683038

Neuner S, Albrecht A, Cullmann D, Engels F, Griess VC, Hahn WA, Hanewinkel M, Hartl F, Kolling C, Staupendahl K, Knoke T (2015) Survival of Norway spruce remains higher in mixed stands under a dryer and warmer climate. Glob Chang Biol 21(2):935-946. doi:10.1111/gcb.12751

Palma CD, Nelson JD (2009) A robust optimization approach protected harvest scheduling decisions against uncertainty. Can J For Res 39(2):342-355. doi:10.1139/X08-175

Pasalodos-Tato M, Mäkinen A, Garcia-Gonzalo J, Borges JG, Lämås T, Eriksson LO (2013) Review. Assessing uncertainty and risk in forest planning and decision support systems: review of classical methods and introduction of new approaches. For Syst 22(2):282. doi:10. 5424/fs/2013222-03063

Petoukhov V, Petri S, Rahmstorf S, Coumou D, Kornhuber K, Schellnhuber HJ (2016) Role of quasiresonant planetary wave dynamics in recent boreal spring-to-autumn extreme events. Proc Natl Acad Sci U S A 113(25):6862-6867. doi:10.1073/pnas.1606300113

Pommerening A (2004) A review of the history, definitions and methods of continuous cover forestry with special attention to afforestation and restocking. Forestry 77(1):27-44. doi:10.1093/forestry/77.1.27

Prestemon JP, Wear DN (2000) Linking harvest choices to timber supply. For Sci 46(3):377-389

Pretzsch H, Block J, Dieler J, Dong PH, Kohnle U, Nagel J, Spellmann H, Zingg A (2010) Comparison between the productivity of pure and mixed stands of Norway spruce and European beech along an ecological gradient. Ann For Sci 67(7):712. doi:10.1051/forest/ 2010037

Pretzsch H, Biber P, Schütze G, Uhl E, Rötzer T (2014) Forest stand growth dynamics in Central Europe have accelerated since 1870. Nat Commun 5:4967. doi:10.1038/ncomms5967

Pretzsch H, Biber P, Uhl E, Dauber E (2015) Long-term stand dynamics of managed spruce-fir-beech mountain forests in Central Europe: structure, productivity and regeneration success. Forestry 88(4): 407-428. doi:10.1093/forestry/cpv013

Pukkala T (2016) Plenterwald, Dauerwald, or clearcut? Forest Policy Econ 62:125-134. doi:10.1016/j.forpol.2015.09.002

Raes L, D'Haese M, Aguirre N, Knoke T (2016) A portfolio analysis of incentive programmes for conservation, restoration and timber plantations in Southern Ecuador. Land Use Policy 51:244-259. doi:10.1016/j.landusepol.2015.11.019

Rahmstorf S, Coumou D (2011) Increase of extreme events in a warming world. Proc Natl Acad Sci U S A 108(44):17905-17909. doi:10. 1073/pnas. 1101766108

Roessiger J, Griess VC, Knoke T (2011) May risk aversion lead to nearnatural forestry? A simulation study. Forestry 84(5):527-537. doi: 10.1093/forestry/cpr017

Roessiger J, Griess VC, Härtl F, Clasen C, Knoke T (2013) How economic performance of a stand increases due to decreased failure risk associated with the admixing of species. Ecol Model 255:58-69. doi:10.1016/j.ecolmodel.2013.01.019

Roessiger J, Ficko A, Clasen C, Griess VC, Knoke T (2016) Variability in growth of trees in uneven-aged stands displays the need for optimizing diversified harvest diameters. Eur J For Res. doi:10.1007/ s10342-015-0935-6

Romero C (2001) Extended lexicographic goal programming: a unifying approach. Omega 29(1):63-71. doi:10.1016/S0305-0483(00) 00026-8

Schütz J-P (2001) Der Plenterwald und weitere Formen strukturierter und gemischter Wälder. Parey, Berlin

Sniedovich M (2012) Fooled by local robustness. Risk Anal 32(10): 1630-1637. doi:10.1111/j.1539-6924.2011.01772.x

Tamiz M, Jones D, Romero C (1998) Goal programming for decision making: an overview of the current state-of-the-art. Eur J Oper Res 111(3):569-581. doi:10.1016/S0377-2217(97)00317-2

Weng YH, Crowe KA, Parker WH, Lindgren D, Fullarton MS, Tosh KJ (2013) Using portfolio theory to improve yield and reduce risk in black spruce family reforestation. Silvae Genetica 62(4-5):232-238

Wilson JS, Baker PJ (2001) Flexibility in forest management: managing uncertainty in Douglas-fir forests of the Pacific Northwest. For Ecol Manag 145:219-227

Yemshanov D, McCarney GR, Hauer G, Luckert MK, Unterschultz J, McKenney DW (2015) A real options-net present value approach to assessing land use change: a case study of afforestation in Canada. Forest Policy Econ 50:327-336. doi:10.1016/j.forpol.2014.09.016

Yousefpour R, Jacobsen JB, Thorsen BJ, Meilby H, Hanewinkel M, Oehler K (2012) A review of decision-making approaches to handle uncertainty and risk in adaptive forest management under climate change. Ann For Sci 69(1):1-15. doi:10.1007/s13595-011-0153-4

Ziemba WT, Mulvey JM (eds) (1998) Worldwide asset and liability modeling. Publications of the Newton Institute, vol vol 10 . Cambridge University Press, Cambridge 